\title{
Nematode control in 'green' ruminant production systems
}

\author{
Peter J. Waller ${ }^{1}$ and Stig M. Thamsborg ${ }^{2}$
}

\author{
${ }^{1}$ Department of Parasitology (SWEPAR), National Veterinary Institute and Swedish University of Agricultural Sciences, SE-751 89, \\ Uppsala, Sweden \\ ${ }^{2}$ Danish Centre for Experimental Parasitology (DCEP), Royal Veterinary and Agricultural University, DK-1870, Frederiksberg C, \\ Denmark
}

\begin{abstract}
Collectively, nematode parasites of domestic ruminants continue to pose the greatest disease problem in grazing livestock systems worldwide, despite the powerful and extensive chemotherapeutic arsenal available for their control. The widespread development of anthelmintic resistance, particularly in nematode parasites of small ruminants, and the trend towards nonchemical (ecological, organic, green) farming of livestock has provided an impetus for the research and development of alternative parasite control methods. This article provides a brief overview of the non-chemotherapeutic options for parasite control and how they might play a role either in organic farming or in other low-input farming systems.
\end{abstract}

The term 'green', as it applies to livestock production systems, refers to low-input operations based on grazing animals on pasture, in contrast to feedlot or housed systems of production. The move back to pasture-based livestock management has received great impetus lately. This is driven particularly by public concerns over handfeeding of food production animals and the bovine spongiform encephalopathy (BSE; 'mad cow') disease scare, the emergence of multi-resistant microbes derived from selection by 'growth promoters' commonly used in the intensive pig and poultry industry, and the entering of chemical residues into the human food chain. In terms of food production, the term 'green' is often combined, or considered synonymous, with 'clean'. This has also provided a stimulus for the rapid expansion of organic agriculture, particularly in Europe, where government subsidies are provided to farmers who opt for this form of production [1]. Statutes developed by various organic farming bodies provide quite rigid stipulations [2], particularly with regard to the use of synthetic compounds (fertilizers, drugs, etc.), and members of the public have a general 'perception of purity' associated with organic food production.

However, for livestock, there is a downside to organic/ green farming. Difficulties have arisen in maintaining adequate control of pasture-borne infectious diseases, particularly those due to nematode parasite infections. Comprehensive investigations have concluded that

\footnotetext{
Corresponding author: Peter J. Waller (Peter.Waller[a]sva.se).
}

Available online 10 August 2004 nematode parasitism is the greatest economic constraint of grazing livestock production, whether in the industrialized [3] or the developing [4] countries of the world. The most profound effects of parasitism are on sub-clinical production loss (i.e. not obvious by visual appraisal) [5], of which farmers - or their advisers - are unlikely to be aware. Assessments of animal health issues associated with organic farming are often based on farmers' perceptions in questionnaires or surveys [6,7], rather than on detailed veterinary investigation. As a consequence, new and serious animal welfare issues might emerge in organic farming that are caused by distress suffered by animals as a result of uncontrolled parasite infections. To counter this, the move to green and organic livestock production has also been accompanied by an increase in research aimed at exploring non-chemical approaches to parasite control [8]. These studies have received a stimulus by the rapid development of resistance to anthelmintic drugs, particularly in nematode parasites of small ruminants $[9,10]$. Non-chemical approaches to nematode parasite control are at varying stages of development, utility and applicability, and can be considered to be targeted either at the parasitic phases within the animal or at the free-living stages on pasture, as discussed here.

\section{Host-stage-directed non-chemical approaches to parasite control}

Genetic resistance of hosts

Genetic resistance is the ultimate in sustainable parasite control. It is a low-cost, permanent solution requiring no extra resources and incurring no additional costs. However, for most species of ruminant livestock, animals that have evolved to be highly resistant to parasite infection are not generously endowed with desirable productivity traits for wool or meat production. These innately resistant breeds are found in the tropics [11], where the formidable combination of malnutrition, environmental stress, long-term and often massive larval challenge and limited relief by way of effective anthelmintic treatment have imposed the harshest conditions for selection, resulting in survival of the fittest [12]. However, attempts are being made to identify those genes that encode parasite resistance in laboratory animal models [13,14]. With the aid of comparative genomic maps, the aim then is to identify the locations of similar genes in ruminants and 
to develop transgenic animals in which genes for resistance are inserted into economically productive breeds.

Even with the more productive, but more-parasitesusceptible, sheep breeds that have evolved in the temperate regions of the world, within-breed selection for nematode resistance has made good progress [15]. This applies even to Merino sheep, which are generally considered to be the most susceptible of all breeds to nematode parasite infection $[16,17]$.

Irrespective of the benefits that have come from the use of host genetics to control nematode infections, progress is likely to be slow (the generation interval of livestock is long), controversial (if transgenic animals are used) and uncertain (there might be side-by-side evolution of parasites to changes in host genotype and/or an inverse relationship between resistance and performance). Predictive modeling will be a valuable tool in this endeavor [18].

\section{Nematode vaccines}

To date, vaccines against nematode parasites have had very limited commercial success. Early forays into this area were made using attenuated whole parasites and, although these showed some promise and marketing opportunities (notably the irradiated larval vaccine of the cattle lungworm, Dictyocaulus viviparus), this approach failed for the important gastrointestinal (GI) nematode parasites of livestock [19]. Attention became focused on the molecular approach of identifying protective antigens against helminth parasites. Although there has been success with such recombinant vaccines against cestodes [20], major barriers still exist for nematodes. These hurdles are complex and interacting, and include the difficulty of producing antigenic fractions of parasite material in commercial quantities and the complexity of the host immune response to parasites, which seems to involve a combination of local hypersensitivity, cellmediated, antibody and inflammatory responses [21]. It is further complicated by the natural unresponsiveness that exists in the young animal ( $<6-9$ months of age) and in the dam around parturition [21,22].

\section{Host nutrition}

The profitability of any grazing livestock industry is driven largely by product output. This translates into raising more animals on any given area to produce more meat, fiber and hides. Thus, man-made changes to herd or flock structure result in more reproducing females and their progeny. For ruminant livestock, both the lactating female and the young animal are the most susceptible to nematode infections. Depending on the age and metabolic condition of animals, food resources are allocated among their body functions such as maintenance, growth and reproduction, but also additional functions that are a direct consequence of parasite infection [23]. Studies on the pathophysiology of internal parasite infection show a metabolic drain caused by an increasing endogenous loss of protein and a reduced efficiency in the utilization of metabolizable energy due to parasite infection [23]. Clearly, the increase in parasite challenge associated with contemporary livestock production systems must come at a price with regards to animal productivity, particularly at times of sub-optimal nutrient supply, when the animal has to prioritize the allocation of scarce nutritional resources. Strategic feed supplementation, particularly to young and peri-parturient animals, can have long-term benefits, and research is now targeted at fine-tuning the ways, means and timing of doing this that would be practical, profitable and, if needed, acceptable to the organic standards [24].

\section{Herbal anthelmintics}

Anthelmintic medication has its origin in the use of plant preparations. In general, these were hazardous concoctions with low anthelmintic efficacy, especially in ruminant species, and they rapidly disappeared from human and veterinary use with the discovery of synthetic anthelmintic compounds [25].

Although a large and diverse range of herbal de-wormers is used throughout the world, particularly in Asian and African countries, generally there is a lack of scientific validation of the purported anthelmintic effects of these products. In ruminants, the claimed efficacy is often associated with farmers observing the occasional elimination of tapeworm segments, which has little bearing on production, let alone parasite control.

There is considerable and apparently expanding interest worldwide in traditional health practices in both the industrialized and developing countries of the world [26], including herbal de-wormers [25,27]. A role for these compounds in the green farming movement of developed countries is difficult to envisage because marketing of products with a high level of efficacy will inevitably be accompanied by regulatory requirements on residue levels, human safety, and so on, and will then, particularly in the organic farming context, become quasi-natural and regarded as medical prevention. However, for resource-poor farmers in developing countries, traditional herbal remedies based on local plants offer an alternative to the expensive and often inaccessible commercial anthelmintics. Studies are now under-way to evaluate some of the "best candidates' used as livestock de-worming preparations by resource-poor communities in East Africa or Asia [28-30].

A particular group of compounds, the cysteine proteinases, has been mentioned as having potential for a novel group of anthelmintics, as they might damage the cuticle of nematodes [31]. The parent compounds are present in plants such as papaya, pineapple and figs, and have a documented effect in several host species against a variety of nematodes. However, their mode of action is not very specific and the safety index (maximum tolerated dose/ recommended therapeutic dose) is expected to be low.

\section{Nutraceuticals}

This refers to crops containing plant secondary metabolites (or nutricines), which are considered for their beneficial effect upon health rather than their direct contribution to the nutrition of animals. The crops are either grazed or fed after preservation, with the main purpose of reducing parasite infections, and ideally they can be incorporated into crop rotation schemes.

A specific group of plant polyphenols, the condensed tannins, has attracted attention in recent years. Initial 
studies in sheep showed that grazing leguminous crops rich in these compounds resulted in reduced levels of GI nematode infections [32]. The main effect of dietary condensed tannins in both sheep and goats seems to be a reduction in fecal egg counts, often in the order of 50-60\%, based on a combination of reduced worm fecundity and elimination of adult worms [33-37]. They might also play a role in reducing the establishment of incoming larvae. The effect on worm burdens is variable and apparently species dependent. For example, the administration of quebracho, an extract of condensed tannins, might reduce nematode burdens of the small intestine (Trichostrongylus colubriformis), but not those of the abomasum (Haemonchus contortus; Teladorsagia circumcincta) [38]. This is supported by findings in goats [36,37]. The epidemiological importance of reduced fecal egg counts continues to be investigated.

Grazing of chicory (Cichorium intybus) by infected sheep has shown some promising results, in particular with regard to reductions in abomasal worm burdens $[39,40]$. Chicory is not a tannin-rich crop but it contains other compounds (e.g. sesquiterpene lactones), which have demonstrated antiparasitic properties in vitro [41].

The variable outcome of many studies using nutraceuticals is probably related to many factors affecting the production (quantity and composition) of secondary metabolites in the crops: soil type, climate, season, cultivar, cutting, grazing, and so on. More knowledge on these factors and on interactions with host nutrition is necessary for future utilization. However, in certain areas (e.g. the Mediterranean region of Europe), there is a long tradition of growing tanninrich legumes such as sulla (Hedysarum coronarium) and sainfoin (Onobrychus viciifolia); thus, the nutraceutical approach to parasite control is worth pursuing.

\section{Free-living-stage-directed non-chemical approaches to parasite control \\ Grazing management}

For decades, various grazing management practices have been the cornerstone of epidemiologically based parasite control strategies in the temperate regions of the world. Not only were they cost efficient and highly effective, particularly when combined with anthelmintic treatment, but they also provided the opportunity for dual livestock species parasite control, such as with sheep/cattle interchange grazing [42]. These concepts became established in the applied veterinary parasitology jargon, with the epithet of 'dose-and-move strategies'. Although this combination of anthelmintic treatment with a move of animals to pastures with low infectivity proved to be highly effective from a parasite control standpoint, it later became apparent in certain localities that these procedures selected strongly for anthelmintic resistance in surviving parasites". However, it has been shown that not all grazing management strategies to control parasites need to be accompanied by anthelmintic treatment to achieve extremely good levels of parasite control for either young cattle [5,43] or sheep [44]. A word of caution also

\footnotetext{
* Besier, R.B. (1999) New strategies to reduce selection for macrocyclic lactone resistance in sheep nematodes. Proceedings of the Australian Sheep Veterinary Society meeting held in Indooroopilly, Queensland, Australia.

needs to be raised on relying on long-term sheep/cattle interchange systems: there have been reports that parasites primarily of cattle might show an increased ability to infect sheep and cause clinical disease [42].

In comparison with the temperate regions of the world, there are relatively few examples of grazing management schemes in the tropics/subtropics, even though their potential might be even greater in this region. This is because, despite the fact that development of the freeliving stages of parasites is generally faster and more successful than in the temperate regions, their longevity is much shorter. Highly successful grazing systems have been developed whereby sheep (or goats) are moved to a new area of pasture after 3-4 days of grazing and are not returned to this area for approximately one month $[42,44]$.

\section{Biological control}

Currently, the work on biological control of nematode parasites of livestock is almost exclusively associated with the nematode-destroying microfungus Duddingtonia flagrans. The microfungus has three very important attributes: (i) the ability to survive gut passage of livestock; (ii) the propensity to grow rapidly in freshly deposited dung; and (iii) the possession of a voracious nematophagous capacity [45]. This fungus thus breaks the life cycle by capturing infective larval stages before they migrate from dung to pasture, where they would otherwise be acquired by grazing animals.

Field evaluation of this concept for a range of livestock species, in a variety of geo-climatic regions, has been under-way for the past decade $[10,45,46]$. At the same time, several potential stumbling blocks on the path towards product registration have largely been overcome. First, it is now possible to produce large quantities of $D$. flagrans spore material; second, long-term field trials using $D$. flagrans have shown no adverse effects on the environment; and third, it has been established that D. flagrans is ubiquitous and that very close genetic similarity exists between isolates from all regions of the world [10].

The commonly used means of deployment of $D$. flagrans spore material is by a feed additive. To achieve optimal results, the fungal spores need to be continuously shed in the dung of animals at the same time that contamination of pasture with parasite eggs occurs [45]. Thus, daily supplementation of fungal material is recommended during the predetermined period of time that biological control is to be effected [10]. Clearly, much greater opportunities for this innovation would occur if effective methods of $D$. flagrans depot delivery were available. Although work has been conducted aimed at developing fungal feed blocks [47,48], and fungal-controlled release devices [49], at this stage none of these prototype devices provide the effective parasite control (continuous spore release) for the minimum required time of at least two months in temperate environments.

\section{The future}

Owners of livestock who opt for organic farming, whether they be simply 'lifestyle' focused or in the business of developing or maintaining profitable enterprises, cannot 
abandon the use of chemotherapy and expect to achieve good health and performance in their animals without implementing other means of control. Inevitably, animal productivity will suffer, which might well lead to serious animal welfare problems, due principally to pasture-borne nematode parasites. Livestock owners need to be well informed, or willing to seek expert advice, on ways to manage their flocks or herds in relation to the epidemiology and impact of parasite infections in different ages, or classes, of animals.

The range of non-chemical approaches to nematode parasite control outlined in this brief review varies in their utility, stage of development, practicality and relevance. Also, the type of livestock enterprise and the country/ region of the world will have a bearing on their adoption. However, one thing is certain: no single method on its own can be expected to provide satisfactory, sustainable parasite control more-or-less indefinitely. The challenge therefore is to utilize a combination of these strategies, yet importantly to recognize that there should be pragmatic flexibility in these programs, allowing for the possible need of occasional, selective use of effective anthelmintics.

\section{Acknowledgements}

Part of this work has been supported financially by the European Union through the project: 'Worm control in organic production systems for small ruminants in Europe - towards the implementation of non-chemical sustainable approaches' (WORMCOPS; contract QLK5-CT 2001-1843).

\section{References}

1 Anonymous (1999) En hållbar utveckling av landsbygden, m.m. (Sustainable development of the Swedish countryside), Stockholm, Government Bill 1999/2000, p. 14

2 Thamsborg, S.M. et al. (1999) Integrated and biological control in organic and conventional production systems. Vet. Parasitol. 84, 169-186

3 Perry, B.D. and Randolph, T.F. (1999) Improving the assessment of the economic impact of parasitic diseases and of their control in production animals. Vet. Parasitol. 84, 145-168

4 Perry, B.D. et al. (2002) Investing in Animal Health Research to Alleviate Poverty. ILRI, International Livestock Research Institute, Nairobi, Kenya,p. 148

5 Dimander, S.O. et al. (2003) Evaluation of gastro-intestinal nematode parasite control strategies for first-season grazing cattle in Sweden. Vet. Parasitol. 111, 193-209

6 Svensson, C. et al. (2000) Parasite control methods in organic and conventional dairy herds in Sweden. Livestock Prod. Sci. 66, 57-69

7 Hovi, M. et al. (2003) Animal health and welfare in organic livestock production in Europe - current state and future challenges. Livestock Prod. Sci. 80, 41-53

8 Waller, P.J. (1999) International approaches to the concept of integrated control of nematode parasites of livestock. Int. J. Parasitol. 29, 155-164

9 Sangster, N.C. (1999) Anthelmintic resistance: past, present and future. Int. J. Parasitol. 29, 115-124

10 Waller, P.J. (2003) Global perspectives on nematode parasite control in ruminant livestock: the need to adopt alternatives to chemotherapy, with the special emphasis on biological control. Animal Health Rev. 4, $35-43$

11 Baker, R.L. (1998) A review of genetic resistance to gastrointestinal nematode parasites in sheep and goats in the tropics and evidence for resistance in some sheep and goat breeds in sub-humid coastal Kenya. Anim. Genetic Resources Information 24, 13-30

12 Baker, R.L. et al. (2003) Exploring the genetic control of resistance to gastrointestinal helminth infections in sheep and mice. Anim. Breed. Genet. 15, 183-190

13 Behnke, J.M. et al. (2000) Mapping genes for resistance to gastrointestinal nematodes. Acta Parasitol. 45, 1-13
14 Iraqi, F.A. et al. (2003) Chromosomal regions controlling resistance to gastrointestinal nematode infections. Mamm. Genome 14, 1-8

15 McEwan, J.C. et al. (1997) The selection of sheep for natural resistance to internal parasites. In Sustainable Control of Internal Parasites in Ruminants (Barrell, G.K. ed.), pp. 161-182, Lincoln University, Canterbury, New Zealand

16 Eady, S.J. et al. (1998) Resistance to gastrointestinal parasites in Merino sheep: correlation with production traits. Aust. J. Agric. Res. 49, 1201-1211

17 Woolaston, R.R. and Windon, R.G. (2001) Selection of sheep for response to Trichostrongylus colubriformis larvae: genetic parameters. Anim. Sci. 73, 41-48

18 Bishop, S.C. and Stear, M.J. (2003) Modeling of host genetics and resistance to infectious diseases: understanding and controlling nematode infections. Vet. Parasitol. 115, 147-166

19 Bain, R.K. (1999) Irradiated vaccines for helminth control in livestock. Vet. Parasitol. 29, 185-191

20 Lightowlers, M.W. et al. (2003) Vaccination against cestode parasites: anti-helminth vaccines that work and why. Vet. Parasitol. $115,83-123$

21 Smith, W.D. (1999) Prospects for vaccines of helminth parasites of grazing ruminants. Int. J. Parasitol. 29, 17-24

22 Knox, D.P. (2000) Development of vaccines against gastrointestinal nematodes. Parasitology 120, S43-S61

23 Coop, R.L. and Kyriazakis, I. (1999) Nutrition-parasite interaction. Vet. Parasitol. 84, 187-204

24 Van Houtert, M.F. (1997) Effects of diet on gastrointestinal nematode infection in ruminants. In Sustainable Control of Internal Parasites in Ruminants (Barrell, G.K. ed.), pp. 183-192, Lincoln University, Canterbury, New Zealand

25 Waller, P.J. et al. (2001) Plants as de-worming agents of livestock in the Nordic countries: historical perspective, popular beliefs and prospects for the future. Acta Vet. Scand. 42, 31-44

26 Schillhorn van Veen, T.W. (1997) Sense or nonsense? Traditional methods of animal parasitic disease control. Vet. Parasitol. 71, 177-194

27 Hammond, J.A. et al. (1997) Prospects for plant anthelmintics in tropical veterinary medicine. Vet. Res. Commun. 21, 213-228

28 Githiori, J.B. et al. (2002) Anthelmintic activity of preparations derived from Myrsine africana and Rapanea melanophloeos against the nematode parasite Haemonchus contortus of sheep. J. Ethnophamacol. 80, 187-191

29 Githiori, J.B. et al. Evaluation of anthelmintic properties of some plants used as livestock dewormers against Haemonchus contortus infections in sheep. Parasitology (in press)

30 Hördegen, P. et al. (2003) The anthelmintic efficacy of five plant products against gastrointestinal trichostrongylids in artificially infected lambs. Vet. Parasitol. 117, 51-60

31 Stepek, G. et al. (2004) Natural plant cysteine proteinases as anthelmintics. Trends Parasitol. 20, 322-327

32 Niezen, J.H. et al. (1998) Production, faecal egg counts and worm burdens of ewe lambs which grazed six contrasting forages. Vet. Parasitol. 80, 15-27

33 Athanasiadou, S. et al. (2000) Consequences of long-term feeding with condensed tannins on sheep parasitized with T. colubriformis. Int. J. Parasitol. 30, 1025-1033

34 Athanasiadou, S. et al. (2000) Effects of short term exposure to condensed tannins on adult T. colubriformis. Vet. Rec. 146, 728-732

35 Kahiya, C. et al. (2003) Effect of Acacia nilotica and Acacia karoo diets on Haemonchus contortus infection in goats. Vet. Parasitol. 115, 265-274

36 Paolini, V. et al. (2003) Effects of condensed tannins on established populations and on incoming larvae of Trichostrongylus colubriformis and Teladorsagia circumcincta in goats. Vet. Res. 34, 331-339

37 Paolini, V. et al. (2003) Effects of condensed tannins on goats experimentally infected with Haemonchus contortus. Vet. Parasitol. $113,253-261$

38 Athanasiadou, S. et al. (2001) Direct anthelmintic effects of condensed tannins towards different gastrointestinal species: in vitro and in vivo studies. Vet. Parasitol. 99, 205-219

39 Knight, T.L. et al. (1996) Effect of pasture species on internal parasites of lambs. Proc. NZ Grassland Assoc. 58, 59-62

40 Marley, C.L. et al. (2003) The effect of birdsfoot trefoil (Lotus 
corniculatus) and chicory (Cichorium intybus) on parasite intensities and performance of lambs naturally infected with helminth parasites. Vet. Parasitol. 112, 147-155

41 Molan, A.L. et al. (2000) Effects of condensed tannins and sesquiterpene lactones extracted from chicory on the viability of deer lungworm larvae. Proc. NZ Soc. Anim. Prod. 60, 26-29

42 Barger, I.A. (1999) The role of epidemiological knowledge and grazing management for helminth control in small ruminants. Int. J. Parasitol. 29, 41-47

43 Nansen, P. et al. (1988) Grazing pressure and acquisition of O. ostertagi in calves. Vet. Parasitol. 27, 325-335

44 Waller, P.J. Sustainable nematode parasite control strategies for ruminant livestock by grazing management and biological control. Anim. Feed Sci. Technol. (in press)
45 Larsen, M. (1999) Biological control of helminths. Int. J. Parasitol. 29, 139-146

46 Anonymous (2002) Biological control of nematode parasites of small ruminants in Asia. FAO Animal Production and Health Paper, p. 104

47 Waller, P.J.et al. (2001) The potential of nematophagous fungi to control the free living stages of nematode parasites of sheep: feeding and block studies with Duddingtonia flagrans. Vet. Parasitol. 102, 321-330

48 Chandrawathani, P. et al. (2003) Biological control of nematode parasites of small ruminants in Malaysia using the nematophagous fungus Duddingtonia flagrans. Vet. Parasitol. 117, 173-183

49 Waller, P.J. et al. (2001) The potential of nematophagous fungi to control the free-living stages of nematode parasites of sheep: towards the development of a fungal controlled release device. Vet. Parasitol. $102,321-330$

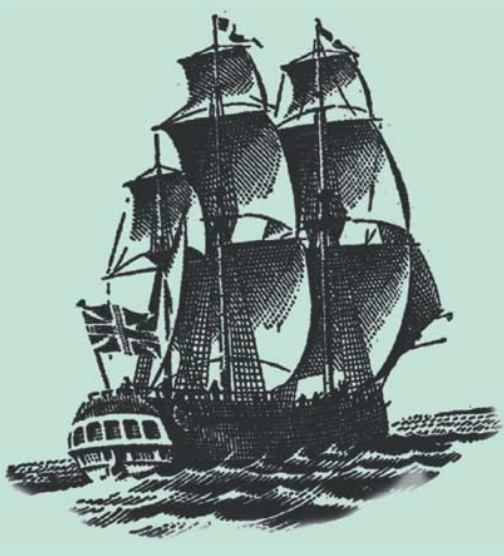

\section{Endeavour}

the quarterly magazine for the history and philosophy of science

You can access Endeavour online via ScienceDirect, where you'll find a collection of beautifully illustrated articles on the history of science, book reviews and editorial comment.

\section{Featuring}

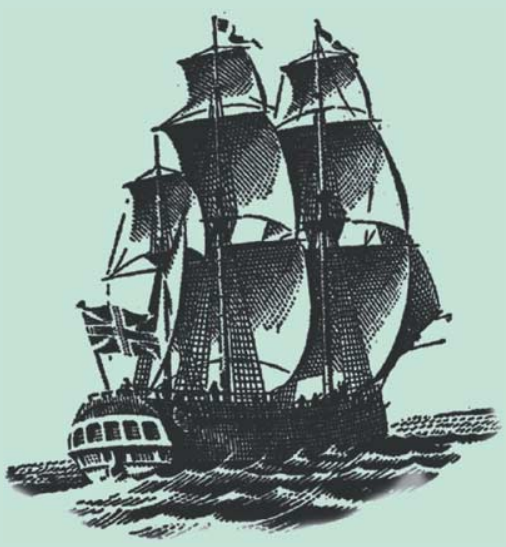

Sverre Petterssen and the Contentious (and Momentous) Weather Forecasts for D-Day, 6 June 1944 by J.R. Fleming Food of Paradise: Tahitian breadfruit and the Autocritique of European Consumption by P. White and E.C. Spary Two Approaches to Etiology: The Debate Over Smoking and Lung Cancer in the 1950s by M. Parascandola Sicily, or sea of tranquility? Mapping and naming the moon by J. Vertesi

The Prehistory of the Periodic Table by D. Rouvray

Two portraits of Edmond Halley by P. Fara

and coming soon

Fighting the 'microbe of sporting mania': Australian science and Antarctic exploration in the early twentieth century by $P$. Roberts

Learning from Education to Communicate Science as a Good Story by A. Negrete and C. Lartigue The Traffic and Display of Body Parts in the Early-19th Century by S. Alberti and S. Chaplin

The Rise, Fall and Resurrection of Group Selection by M. Borrello

Pomet's great "Compleat History of Drugs" by S. Sherman

Sherlock Holmes: scientific detective by L. Snyder

The Future of Electricity in 1892 by G.J.N. Gooday

The First Personal Computer by J. November

Baloonmania: news in the air by M.G. Kim

and much, much more ...

Locate Endeavour on ScienceDirect (http://www.sciencedirect.com) 